\title{
HACIA UNA SOCIOLOGIA DE LA ANCIANIDAD EN ESPAÑA
}

Ignacio Casals

La preocupación por la temática gerontológica responde a un motivo claro: a la importante proporción de ancianos en los países desarrollados y al hecho de que esta proporción aumente año tras año. Los viejos (y las viejas) representan unos costes sociales considerables, estando además sobrerrepresentados en los sistemas de asistencia social y sobre todo en sanidad y seguridad social. La importancia del hecho del envejecimiento de la población ha provacado la generación de una voluminosa bibliografía sobre el tema analizando aspectos médicos, psicológicos o sociológicos. Los estudios que tratan el tema gerontológico en su conjunto, normalmente con un enfoque sociológico, son en bastantes casos más descriptivos que analíticos. Se llega a una descripción de la realidad, pero no se explica por qué las cosas son así y cuáles son los mecanismos sociales que conducen a ello. En consecuencia, las soluciones propuestas y aplicadas en la realidad tienden a solucionar los efectos ya que las causas son desconocidas. Se hace, pues, imprescindible un análisis sociológico de la situación social de las ancianas y ancianos, y más particularmente en nuestro país.

Las presentes notas pueden considerarse un esquema programático de la investigación a realizar sobre unos cuantos aspectos importantes que atañen 
a los ancianos españoles '. Repito que este análisis debe ser cualitativo. No basta con saber cuántos ancianos tenemos o cuántas residencias ponemos a su disposición; es necesario analizar todo ello a través de la perspectiva de la estructura social en su conjunto, de los intereses objetivos de la sociedad y de las diferencias entre clases sociales. Este es un terreno en el que crónicamente ha habido una dicotomía entre una ideología verborreica (la ancianjdad excelsa, dulce consejera, remanso de paz) y las actuaciones concretas que se aplicaban. No sirve de nada, por ejemplo, prometer pensiones y hacer creer a la población que acumula «derechos» si no se está seguro de que se podrán atender dichos derechos. Algunos de estos interrogantes básicos son los que se ofrecen a continuación. Las respuestas requerirán un largo tiempo de estudio.

\section{La ancianidad en la bistoria}

No es posible generalizar para todas las culturas por lo que respecta a la suerte de los ancianos en las comunidades primitivas. No obstante, el anciano tiene más posibilidades de subsistir en las sociedades ricas que en las pobres, en las sedentarias que en las nómadas, aunque la situación económica no es absolutamente determinante. Gran importancia tiene, por ejemplo, la buena relación familiar entre padres e hijos, que salva a los viejos de la norma más habitual que es la de eliminarlos. La religión, la magia y la acumulación de conocimientos eran también muy importantes siempre que el viejo estuviera sano; si no, difícilmente se le respetaba ${ }^{2}$.

La situación de los ancianos no cambió mucho a lo largo de la historia. En todas las culturas encontramos una serie de constantes histórico-sociales. En las sociedades guerreras o en período de evolución todo el poder estaba en manos de los jóvenes; los viejos no tenían mucho poder, a lo sumo papeles simbólicos. En cambio, en las sociedades estables se instauró el derecho de propiedad, que ya no dependía de la fuerza y al amparo del cual la vejez adquirió poder creciente. En cualquier caso la vejez no era casi nunca envidiada, todo lo más respetada o temida, sino que por el contrario, aun en el mejor de los casos, el viejo era una persona a la que se consideraba fuera de este mundo y al que, por tanto, se le prohibía disfrutar de los placeres de la vida. Naturalmente, ello se recubría con el lenguaje de «venerable»,

1 El presente artículo es en realidad un resumen del texto: Ignacio Casals, Sociología de la ancianidad en España (Barcelona: mimeo, 1979). El texto fue presentado a la Facultad de Ciencias Económicas de la Universitat Autónoma de Barcelona como tesina de licencia.

El lector encontrará en el texto un mínimo de notas y al final una relación de la bibliografía utilizada.

- A lo largo de este primer punto se han tomado numerosas notas, entre otros, del texto: Simone dE BEAUvoIR, La vejez (Buenos Aires: Editorial Sudamericana, 1970). 
«superación de las pasiones», «prudencia», «austeridad», pero en realidad el anciano estaba muerto para estas sociedades. En el peor de los casos era burlado y vilipendiado cruelmente. Cuando las condiciones económicas eran malas, la situación del anciano era miserable. Con frecuencia, desde los pueblos primitivos hasta el siglo xIX el anciano era asesinado, a veces con odio, a veces con cariño, pero las condiciones sociales de vida se imponían inexorablemente.

La conclusión principal que puede ya sacarse a lo largo de la historia, pero que con el aumento cuantitativo de ancianos en el modo de producción capitalista se ve más claramente, es la diferencia de situación entre ancianos ricos y pobres. La clase social es el factor esencial para determinar la actitud de la sociedad con respecto a uno o a otro, y la situación objetiva con respecto a la enfermedad y la muerte.

\section{Dinámica demográfica actual}

Causas endógenas del envejecimiento

Las causas endógenas de envejecimiento mencionadas más a menudo son: el progreso de la medicina, la mejor alimentación, la mejor calidad de vida -higiene, vivienda-, el desarrollo socioeconómico, el descenso de la mortalidad y el descenso de la natalidad

La mejora de la alimentación de una población, las medidas de higiene, así como los progresos en la calidad de la vida, son factores que tienden a alargar la vida del individuo y, por tanto, incrementan la cantidad de personas que llegan a la tercera edad. La aportación de la medicina tiene lugar sobre todo en la reducción de la mortalidad infantil, con la ayuda de los factores sociales ya enunciados. Si los niños y las niñas no mueren y además encuentran mejores condiciones de vida, llegan a edades más avanzadas. Todo ello son causas que incrementan la cantidad de ancianos.

El razonamiento seguido hasta ahora no justifica el envejecimiento de la población que se mide no por la cantidad de personas ancianas, sino por la proporción de las mismas. Lógicamente, si los recién nacidos no mueren, cuando antes lo hacían gran parte de ellos, debería haber una amplia base en la pirámide de edades de la población, con lo que el equilibrio entre generaciones se mantendría. Pero precisamente es eso lo que no ocurre. Se produce una reducción de nacimientos que hace disminuir proporcionalmente el número de niñas y niños, y por el otro extremo de la pirámide aumenta el de personas ancianas. No es, pues, el descenso en la mortalidad lo que hace envejecer a una población dada, sino más bien el descenso de la na. talidad.

Factores exógenos

Son factores exógenos en la distribución por edades de una población 
aquellos que son debidos a causas que dependen de acontecimientos políticos (como las guerras) o de la situación laboral de un país (es decir, las migraciones). Ambos factores tienen importancia en la comprensión de la pirámide de edades española (gráfico 1 ).

\section{GRAFICO 1}

\section{Pirámide de edad española}

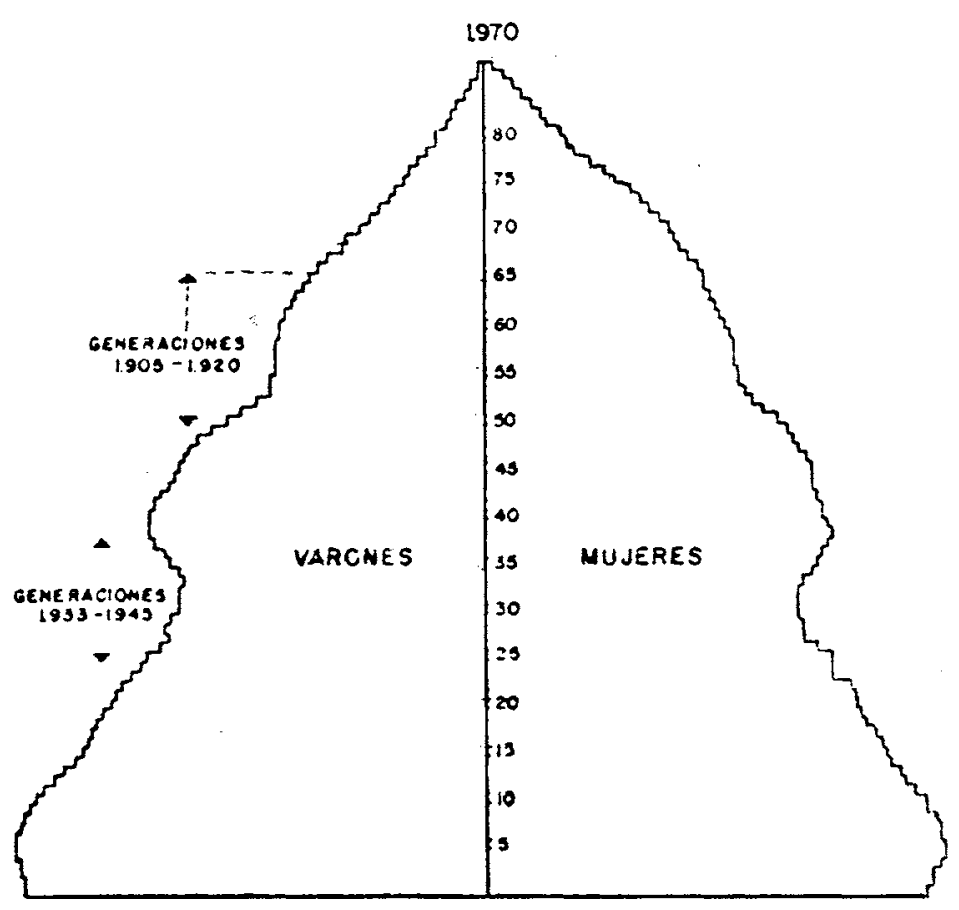

FUente: Fundación FOESSA, Comp. Estudios Sociológicos sobre la situación social de España, 1975 (Madrid: Euramérica. 1976), pág. 11.

La Guerra Civil se refleja claramente en la pirámide. Las generaciones de 1905 a 1920 fueron las que hicieron la guerra y las que más fuertemente sufrieron sus consecuencias políticas posteriores. Si bien para algunos, por ejemplo Angel Carrión ${ }^{3}$, fueron más de un millón de personas las que dejaron de existir de una manera anormal en el período 1936-1945, para otros,

"Angel Carrión Garzapán, cap. 1, "La población española y su territorio", páginas 3-56, en: Fundación FOESSA, Estudios sociológicos sobre la situación social de España, 1975 (Madrid: Euramérica, 1975). 
como Jesús M. de Miguel ${ }^{4}$, esta afirmación es exagerada y la cantidad debió ser notablemente inferior. Este último autor añade que dicha generación produjo un descenso en el número de nacimientos - muesca inferior de la pirámide- porque en su período fértil eran menos numerosos, y que ello venía agravado porque dicha generación provenía de otra que sufrió el cólera de 1917 y ésta, a su vez, de otra que hizo la guerra de Cuba, con lo que se han producido históricamente una serie de hechos que han incidido sobre unas generaciones concretas.

Las emigraciones han sido en la historia de España, en general, un fenómeno importante demográficamente, y más aún en el siglo $\mathrm{xx}$. Si bien es cierto que la emigración se produce en las edades jóvenes de la vida, también lo es que al ser una tendencia continuada es muy posible que el conjunto de los emigrantes, con sus descendientes, nos permitiese dibujar una pirámide de edad similar a la española. Se puede estimar que las repercusions a nivel de toda España son prácticamente inexistentes.

Otro problema es el de los desequilibros regionales provocados por las migraciones internas dentro de la Península. Si en 1900 las diferencias en la tasa de envejecimiento eran pequeñas entre las provincias, como máximo de 2,4 puntos, a partir de 1960 empiezan a ser considerables y van agudizándose cada vez más hasta 1980. Provincias como Avila, Cuenca, Guadalajara, Huesca, Lugo, Orense, Soria, Teruel y Zamora superarán en 1980 la tasa de envejecimiento del 15 por 100. En cambio, otras como Alava, Almería, Guipúzcoa, Málaga, Murcia, Las Palmas, Santa Cruz de Tenerife, Sevilla, Valladolid y Vizcaya no pasarán del 9,7 por 100 , que era la tasa para 1970. Madrid y Barcelona tendrán 9,7 y 10 por 100, respectivamente. Entre los años 1960 y 1970 , casi cuatro millones de personas se trasladaron a otras regiones de España. De ellas sólo el 4 por 100 eran mayores de 65 años.

\section{Datos generales sobre el envejecimiento español}

La esperanza de vida de los españoles ha aumentado considerablemente a lo largo de este siglo. Al año cumplido, dejando aparte por tanto la mortalidad infantil que ha afectado antes de ese momento, la esperanza de vida ha aumentado en 30,5 años en el período 1900-1970. Este aumento, en cambio, ha sido de 5,6 años para los mayores de 65 años y de 3,9 para los mayores de 75 . Es decir, gracias a los progresos de la medicina y la mejora en las condiciones de vida, se consigue que la mayoría de la población llegue a anciana. Lo que no se ha conseguido es alargar espectacularmente la vida a los ancianos. Puede dudarse fundadamente que al equilibrio del sistema social le interese alargar mucho la vida de los ancianos. Es importante profundizar

4 Jesús M.a DE Miguel, El ritmo de la vida social (Madrid: Tecnos: 1973 ). 
en este punto y realizar suposiciones de lo que ocurriría en esas circunstancias.

La población ha aumentado en 1900-1970 en un 87 por 100, es decir, poco más del 1 por 100 anual, en una especie de línea continua con pequeos altos y bajos ( tabla 1). Este crecimiento está dentro de los límites aceptados para los países desarrollados y supone duplicar la población cada cien años. Paralelamente, la población anciana ha aumentado un 240 por 100 y ha pasado de ser un 5,3 a un 9,7 por 100 de la población total. La causa la encontramos en el análisis de las columnas de natalidad y mortalidad. Si la natalidad hubiera disminuido como lo ha hecho y la mortalidad fuera la de 1900 , desde 1930 tendríamos una población en regresión y una tasa de envejecimiento aún mayor, pero ello no ha ocurrido nunca porque la natalidad sólo ha disminuido en la medida que lo ha hecho la mortalidad, o por lo . menos la mortalidad infantil. En el caso que podría parecer más verosímil de que la natalidad fuera la misma de 1900 y la mortalidad hubiera ido descendiendo, España hubiese tenido en 1970 alrededor de 50 millones de habitantes y los ancianos habrian representado entonces alrededor de un 7 por 100 de la población. Es decir, que el incremento en la tasa de ancianos se debe principalmente a las niñas $\mathrm{y}$ niños pequeños que no han nacido.

El sexo influye también de una manera importante en la duración de la vida de una persona y, por tanto, en el envejecimiento. La esperanza de vida al nacer era en 1970 de 69 años para los varones y de 74 para las mujeres, siendo ésa una diferencia ya clásica que se ha ido acentuando, en años, a medida que ha ido avanzando el siglo. Por cada 100 personas ancianas hay aproximadamente de 40 a 45 varones y de 55 a 60 mujeres, pero esta proporción se va desequilibrando con la edad debido a la mayor mortalidad masculina. Así, según estimaciones del informe GAUR ${ }^{5}$, en 1971 la distribución varones-mujeres era entre 65 y 69 años de 43-57; entre los 70 y 79 , de 42-58; entre 75 y 79, de 40-60, y a partir de los 80, 35-65. Las personas muy ancianas son en su mayor parte mujeres. A este fenómeno se le dan explicaciones tanto de tipo fisiológico (la mayor fortaleza de la mujer) como sociales (el más rápido deterioro del varón debido a sus funciones sociales, que son más peligrosas o que producen mayor stress).

\section{La sociedad industrial}

La ancianidad es un fenómeno de países industrializados no porque la industria sea la causante, sino porque a la industrialización precede o acompaña la explosión demográfica, la higiene, los descubrimientos de la ciencia mé-

Gaur, La situación del anciano en España (Madrid: Confederación Española de Cajas de Ahorros, 1975). 


\section{TABLA 1}

Algunos indicadores demográficos de la población española (1900-1980)

\begin{tabular}{|c|c|c|c|c|c|c|}
\hline$A \tilde{n} \circ \mathrm{s}$ & $\begin{array}{l}\text { Población } \\
\text { total } \\
\text { (miles) }\end{array}$ & $\begin{array}{l}\text { Población de } \\
65 \text { y más años } \\
\text { (miles) }\end{array}$ & $\%$ más 65 años & $\begin{array}{c}\text { Tasa de } \\
\text { natalidad } \\
\text { (por } 1.000 \text { hab.) }\end{array}$ & $\begin{array}{c}\text { Tasa de } \\
\text { mortalidad } \\
\text { (por } 1.000 \text { hab.) }\end{array}$ & $\begin{array}{c}\text { Crecimiento } \\
\text { vegetativo anual } \\
\text { promedio } \%\end{array}$ \\
\hline $\begin{array}{llllllll}1900 & \ldots & \ldots & \ldots & \ldots & \ldots & \ldots & \ldots\end{array}$ & 18.168 & 967,8 & 5,3 & 33,8 & 28,8 & 0,5 \\
\hline $\begin{array}{llllllll}1910 & \ldots & \ldots & \ldots & \ldots & \ldots & \ldots & \ldots\end{array}$ & 19.996 & $1.105,6$ & 5,5 & 32,6 & 22,9 & 1,0 \\
\hline $\begin{array}{llllllll}1920 & \ldots & \ldots & \ldots & \ldots & \ldots & \ldots & \ldots\end{array}$ & 21.390 & $1.216,6$ & 5,7 & 29,3 & 23,2 & 0,6 \\
\hline $\begin{array}{llllllll}1930 & \ldots & \ldots & \ldots & \ldots & \ldots & \ldots & \ldots\end{array}$ & 23.678 & $1.440,7$ & 6,1 & 28,2 & 16,8 & 1,1 \\
\hline $\begin{array}{llllllll}1940 & \ldots & \ldots & \ldots & \ldots & \ldots & \ldots\end{array}$ & 25.878 & $1.690,4$ & 6,5 & 24,2 & 16,5 & 0,8 \\
\hline $\begin{array}{llllllll}1950 & \ldots & \ldots & \ldots & \ldots & \ldots & \ldots & \ldots\end{array}$ & 29.977 & $2.022,5$ & 6,7 & 20,0 & 10,8 & 0,9 \\
\hline $\begin{array}{llllllll}1960 & \ldots & \ldots & \ldots & \ldots & \ldots & \ldots & \ldots\end{array}$ & 30.528 & $2.505,3$ & 8,2 & 21,6 & 8,6 & 1,3 \\
\hline $\begin{array}{llllllll}1970 & \ldots & \ldots & \ldots & \ldots & \ldots & \ldots\end{array}$ & 34.041 & $3.290,6$ & 9,7 & 19,7 & 8,5 & 1,1 \\
\hline $\begin{array}{llllllll}1980 & \ldots & \ldots & \ldots & \ldots & \ldots & \ldots & \ldots\end{array}$ & 37.876 & $3.791,1$ & 10,7 & $19,0^{-4}$ & $8,4^{4}$ & 1,1 \\
\hline
\end{tabular}

Estimación propia.

Fuentes: Anuario Estadístico de España, 1978 (Madrid: INE, 1978), págs. 50 y 56. Cajas de Ahorros Confederadas, La situación del anciano en España (Madrid: CECA, 1975), págs. 101, 114, 115. 
dica y fundamentalmente el capitalismo. Hay un antes y un después en materia de ancianidad, y esta transición está asociada a la industrialización, al triunfo de la burguesía y al capitalismo. Todo ello ha comportado un gran incremento en el número de ancianos y por tanto un problema nuevo. La situación es similar en los países ocidentales y orientales en tanto en cuanto estén industrializados. El sistema de valores y la organización de la vida presenta características similares.

Los valores culturales del sistema social actual en el modo en que queda enmarcado exaltan la figura del varón sobre la mujer. El problema de la ancianidad tiende, pues, a referirse más a viejos que viejas, cuando éstas son más numerosas y viven más largo tiempo. El valor máximo de la sociedad es la productividad; se mide y se exalta al individuo por lo que es capaz de producir, y se estudian los métodos llamados científicos para conseguir que el rendimiento humano sea máximo en un tiempo mínimo. Naturalmente la población asimila la cultura dominante que mitifica la productividad y al joven como más productivo. Paralelamente, esta misma sociedad desprecia a las personas en cuanto aparentemente su productividad empieza a disminuir, y ello ocurre cada vez a una edad más temprana, ya que el sistema al forzar la producción consume rápidamente la fuerza de trabajo, o se inventan nuevas máquinas para las que se pide gente joven. Ello culmina con la expulsión del sistema de las personas llegadas a una determinada edad, que también cada vez tiende a adelantarse, y los sumerge en un nivel de vida inferior al del resto de la población.

El sistema social queda, pues, amenazado por sus propios principios. La producción cada vez necesita menor aportación humana. Los productos se saturan en el mercado. Las crisis económicas que se suceden dejan sin trabajo a los jóvenes y a las personas mayores de edad aún activa. Los jóvenes no comprenden que un sistema que les ha formado en la productividad no les dé trabajo y exigen que los viejos sean apartados y jubilados. Se produce una pugna por estar presente en el mundo del trabajo, en la que los ancianos tienen las de perder.

Los problemas de la vejez y las políticas sociales de la vejez se refieren casi siempre a viejos-pobres. El viejo del que inconscientemente hablamos es un viejo-pobre, pertenece a los estratos bajos y medios de la sociedad. La diferencia de clases es evidente. El viejo-rico no tiene más problemas que los que derivan de su estado de salud $\mathrm{y}$, por supuesto, tiene muchos más medios para cuidarla. «La tercera edad resume, acentuándolas, todas las desigualdades sociales, ya que la vejez depende de lo que ha sido la vida activa, y... las privaciones, las preocupaciones y la pobreza ayudan a envejecer ${ }^{6}$. Es decir, en el fondo de todo está la lucha de clases y la explotación de la mayoría

${ }^{6}$ I.S.P. A., Informe sociológico sobre la ancianidad en Cataluña (Documento policopiado, Barcelona, 1976), pág. 14. 
por la minoría. Es una explotación no ya en dinero, sino en años de vida y en calidad de esa vida.

\section{El proceso de jubilación}

Existen ópiniones a favor y en contra de la jubilación de los ancianos. Los unos dicen que es necesario hacer un lugar a los jóvenes que tienen que entrar en el mercado de trabajo, ya que éstos reciben salarios más bajos y, por tanto, reducen el precio de los productos de consumo y, al mismo tiempo, las personas mayores encuentran dificultades para adaptarse a los nuevos sistemas. Simone de Beauvoir hace referencia a experiencias inglesas que demuestran que, pasados los 65 años, el 25 por 100 de las personas padecen trastornos patológicos que afectan su movilidad (y en otra encuesta), el 85 por 100 de los jubilados eran en realidad incapaces de proseguir su trabajo aunque lo pretendieron.

Por otro lado, 'existen gran cantidad de opiniones y experiencias que defienden lo contrario. Los más discretos dicen que «a esa edad» es difícil aprender cosas nuevas, pero se pueden seguir haciendo bien las que ya se hacían. Otros adoptan posturas voluntaristas diciendo que la sociedad no debe privarse del enorme capital intelectual, 'moral y cultural que los ancianos han acumulado. Según algunos informes, excepto para oficios muy penosos, hay poca diferencia de rendimiento entre los trabajadores de 50 a 59 años y entre los de 60 y 69. La eficacia sigue siendo muy elevada. De 1.500 obreros de edad que durante 'la última guerra habian prolongado sus actividades, el 59 por 100 de ellos trabajaban tan bien como antes de los 65 años. Los contradictorios resultados en investigaciones de este tipo obligan a ser prudentes en las conclusiones.

$\mathrm{Si}$ bien es cierto que en todas las culturas el viejo era despreciado y reducido a la miseria, el modo de producción industrial es el que ba inventado la jubilación. En el campo la jubilación no es brusca, sino que progresivamente van dejando de hacerse los trabajos más pesados. En las profesiones no vinculadas directamente a la producción industrial, como las liberales y las artes, tampoco la jubilación afecta con tanta brusquedad. La jubilación tampoco existe para los propietarios y patronos, es un privilegio exclusivo de los trabajadores ligados a la producción industrial. La única ventaja teórica que posee el sistema de jubilación es que a nadie se le excluye directamente por ser él, sino por pertenecer a un grupo de edad que debe ser apartado del trabajo. Individualmente es posible no sentirse viejo, pero ello es difícil.

La jubilación de la mujer presenta unas características peculiares $\mathrm{y}$, en general, se adaptan mejor al papel de anciana, fundamentalmente porque nunca trabajaron o porque no ocuparon lugares importantes en el sistema produc- 
tivo. Con frecuencia la mujer considera su trabajo como algo secundario en su vida, debido a que la formación cultural que se le dio conducía a ello. Además, la mujer, acostumbrada a la retirada por muchos fenómenos, biológicos como la menopausia, la pérdida de la belleza, emancipación de los hijos, acepta con mayor serenidad el acercamiento de la vejez.

Verse cambiado bruscamente de la categoría de individuo activo a la de inactivo y ser considerado viejo, sufrir una disminución de los recursos de vida, es, en la inmensa mayoría de los casos, un drama que acarrea graves consecuencias psicológicas y morales. Si la valía del individuo era su producción, ahora no vale nada. No siempre se espera ansiosamente la jubilación, excepto cuando el trabajo era agotador en extremo. EI jubilado está inactivo todo el día y ello puede causarle transtornos físicos y psicológicos. Es inútil hablar de bobbies o de trabajos especiales para ancianos, tipo talleres protegidos; no se trata de que el anciano «se sienta útil», él sabe que no lo es. La única solución dentro del sistema requeriría adaptar las condiciones de trabajo a cada edad del individuo y ello es posible hacerlo, aunque difícil.

El esquema legal español prevé la jubilación de la mujer a los 60 años y la del varón a los 65 . Si bien legalmente el carácter de esta jubilación es voluntario, en la práctica se llega a la jubilación agotado, o el obrero desconoce esta posibilidad, o no se aplica porque en las empresas se concibe esta edad como clave y obligatoria. Por lo demás, la ley no prevé ningún tipo de reducción de actividad, por lo que el trabajo, caso de continuarse, puede resultar gravoso.

Los datos oficiales nos muestran la realidad a la que nos estamos refiriendo. La población activa masculina és muy superior a la femenina. Esta, en cambio, no aprovecha en muchos casos la posibilidad de jubilarse a los 60 años. Los 65 años son una barrera clara para la mitad de los trabajadores y la de los 70 para casi todos. Los que siguen trabajando más allá de los 65 años pertenecen principalmente al sector primario, o son pequeños comerciantes, trabajadores por cuenta propia, profesionales y funcionarios.

Los empresarios sin asalariados, que son el 19 por 100 de la población activa, aportan más de la mitad de los activos mayores de 65 años. Entre los empresarios, aunque lógicamente con un porcentaje menor, también se produce un importante aumento proporcional del 2,5 al 4,6 por 100 . En cambio, los asalariados, que son el 64 por 100 del conjunto de la población activa, sólo representan el 29 por 100 de los activos mayores de 65 años. En 1970 el 27 por 100 aproximadamente de la población no estaba cubierta por la Seguridad Social y, por tanto, en algunos casos no tenían derecho a pensión. Este grupo de población puede ir llegando a los 65 años sin derecho a pensión. Por otro lado, la pensión tipo era en 1978 de unas 150.000 pesetas al año, a las que no todos llegaban - las viudas- y que debía servir en muchos casos para dos personas cuando la renta per capita era de 190.000 pesetas, por lo que incluso con la prohibición de trabajar para tener derecho a la pen- 
sión, muchos se veían y se ven en la obligación de realizar alguna actividad que complemente sus ingresos.

Con frecuencia se habla de la conveniencia de retrasar la edad de la jubilación a fin de que el individuo se sienta útil y productivo. Desde un punto de vista subjetivo las encuestas muestran que un buen número de personas ancianas desearían trabajar, pero muchas veces no se busca la causa de este deseo. ¿No será la penuria económica? Además, aparte de los que siguen trabajando (campesinos, autónomos, profesionales), la mayor parte de las ocupaciones que ofrece la sociedad ¿son realmente apetecibles por alguien? Desde un punto de vista objetivo, no parece probable que a corto o medio plazo interese a los empresarios contratar población anciana. En España, según datos oficiales, el porcentaje de parados de más de 50 años sobre el total va aumentando año tras año. La lógica del capital es clara: mientras exista un ejército de reserva joven y dispuesto al trabajo, no hay motivo para emplear personas de más edad. Las disposiciones oficiales no favorecen tampoco no ya a los ancianos, sino a los maduros. Una disposición de 1979 del Ministerio de Trabajo desgrava costos de seguridad social a aquellas empresas que contraten personas de 16 a 26 años. La medida, por supuesto, no favorece a los ancianos.

\section{Los sitemas de pensiones}

Con frecuencia se oyen voces que piden pensiones más altas para los anciones, pensiones del 100 por 100 del sueldo real del trabajador en el momento de la jubilación, o se critica duramente el elevado grado de miseria a que se ven sometidos los ancianos. Se denuncia también que la ausencia de unos ingresos adecuados afecta a la salud de la persona, y se critican los sistemas de pensiones en general. A nivel teórico es posible que nadie dude de que el anciano debe tener los recursos suficientes para disfrutar una vida digna. Pero ¿qué son recursos suficientes?, ¿qué es una vida digna?, ¿qué inconvenientes tiene el sistema económico? Un análisis teórico-sociológico de los problemas no puede caer en el voluntarismo, sino que deben plantearse todos los aspectos positivos y negativos que influyen en el tema.

Los pensionistas son improductivos, pertenecen a las clases pasivas. Los pensionistas están aumentando cada día en relación a los activos. El dinero que reciben se convierte en víveres, vivienda, ropa y otros consumos. Ello requiere que un número definido de personas esté trabajando para producir los bienes que los ancianos consumen. Como quiera que el número de personas activas va a crecer menos que el de las inactivas en el transcurso de los próximos años a un nivel igual de prestaciones, la carga no disminuirá, sino todo lo contrario. Todo ello tiene, naturalmente, sus repercusiones en el sistema económico, que debe enfrentarse a estos problemas sin disminuir la capacidad adquisitiva de los ancianos. 
Existen cuatro sistemas posibles de conseguir los recursos necesarios para financiar las pensiones. El primero y más tradicional consiste en los seguros de vejez, de tipo particular, que la persona ha financiado durante su vida. El segundo es el que combina las cotizaciones de los trabajadores y de los empresarios a una Caja general. El tercero es igual que el segundo, pero además de las cotizaciones existe una aportación estatal proveniente de los impuestos. El cuarto sistema es el que se financia exclusivamente por los impuestos. De los cuatro sistemas, los tres primeros contemplan una componente individual que es la esencial. La pensión será proporcional a la cotización del trabajador. Ello comporta que después de la jubilación sigan existiendo las considerables diferencias de recursos que existían en el período activo. Los que protestan por esta desigualdad y claman por la unificación de las pensiones no tienen presente que ello equivaldría a una nueva marginación de los ancianos como grupo social. Si existen desigualdades entre los activos debe haberlas también entre los pasivos para que los ancianos sean ciudadanos como los otros. La equiparación de rentas es algo que debe afectar a todas las personas, incluidos los ancianos, y es función del sistema fiscal, no del sistema de pensiones.

Los sistemas de pensiones son relativamente nuevos en la mayoría de los países. Ello comporta que existe gran cantidad de ancianos que no han tenido tiempo de acumular derechos a fin de poder disfrutar de una pensión que les permita sobrevivir. El sistema se desentiende cuanto puede, sabiendo que el tiempo juega a su favor y que mientras se pide y se discute van desapareciendo los casos problemáticos. En poco tiempo todo quedará solucionado... por aniquilación. Aparte de estos casos para los que quizá sería necesaria una solución de compromiso, es posible que los sistemas de pensiones puedan encontrarse con notables inconvenientes provocados por la excesiva acumulación de derechos por parte de las clases pasivas. El sistema de salarios se fija en base a unos precios de mercado en los cuales influyen considerablemente la presión social de la clase trabajadora y que es en buena parte proporcional a las necesidades de la familia media. Es decir, en la medida en que el sistema de salarios y no el sistema fiscal soluciona los problemas sociales, cuando el trabajador deja de tener hijos a su cuidado su salario aumenta proporcionalmente; si además, como ocurre en determinados países, la antigüedad en el puesto de trabajo aumenta el sueldo del trabajador y éste al final de su vida activa se jubila con todos estos derechos adquiridos, las clases activas con menos antigüedad y con hijos a su cargo deberán correr además con el pago de las elevadas pensiones que el sistema posibilita.

En España existen tres fuentes principales de ingresos para los ancianos: el Ministerio de Hacienda para las clases pasivas del Estado, la Seguridad Social para sus pensionistas y el Fondo Nacional de Asistencia Social, también del Gobierno, para los que no tienen ninguna pensión. 
Las clases pasivas del Estado han gozado clásicamente de un trato privilegiado; sus pensiones son como promedio dos veces superiores a las de los demás ancianos. Este trato especial es objetivamente cuestionable: ¿por qué el Estado que obtiene sus recursos de toda la población tiene que favorecer a una pequeña parte de ella?

Las pensiones de la Seguridad Social cubren a la mayor parte de la población anciana. No es una pensión del Estado con cargo a sus presupuestos, sino que beneficia sólo a aquellos que previamente cotizaron. Para tener derecho a pensión se requieren diez años de cotización. Con este tiempo mínimo se tiene derecho al 50 por 100 de la suma de las bases tarifadas de veinticuatro meses seguidos de cotización dividido por 28. Por cada año más de cotización se añaden dos puntos, llegándose en consecuencia al 100 por 100 a los treinta y cinco años de cotización. Este esquema presenta un grave inconveniente. Durante muchos años los empresarios o no aseguraban a sus empleados o lo hacían en cantidades muy inferiores al sueldo real, lo que producía unas pensiones ridículas, las cuales además no eran revisadas periódicamente. Estadísticamente se constata que las personas más ancianas son las que tienen pensiones más bajas. Lo que no parece lógico del sistema, en general, es que cincuenta años de cotización proporcionen los mismos derechos que treinta y cinco. Esto sería lógico en un sistema de pensiones a cargo del Estado, pero no en un sistema de cotización. Por otra parte, el sistema tiene otros dos problemas importantes que pueden poner en peligro su estructura a medio o largo plazo. En primer lugar, parecería más lógico desde un punto de vista económico que la pensión resultante fuera proporcional a la cotización realizada a lo largo de toda la vida - evitando los inconvenientes de la inflación-, ya que en la fórmula actual puede ocurrir que en los dos últimos años se incremente excesivamente la cotización a fin de obtener una pensión mejor, lo que pueden hacer con mucha mayor facilidad los empresarios y profesiones superiores con mayor capacidad de pacto, lo que grava sin compensación alguna las cuentas del seguro y puede llevar a la quiebra. $O$ bien puede darse el caso inverso en el que una persona que habiendo cotizado cantidades considerables durante toda su vida se encuentra al final de su vida con un empleo de categoría inferior del que le resultará una pensión también inferior. Otro problema no previsto es que en el supuesto del sistema a pleno funcionamiento, como lógicamente los salarios de las personas van aumentando con la edad (en una primera etapa por perfeccionamiento profesional y posteriormente al menos por antigüedad), un 10 por 100 de la población anciana puede obtener un 12, un 13 por 100 o más de las rentas salariales, lo cual, sin duda, obligará a aumentar las cotizaciones a los activos y por tanto a disminuir su sueldo neto y su poder adquisitivo.

En la actualidad no se presentan todavía estos problemas, pero no obstante las pensiones consumen una buena parte de los presupuestos de la Seguridad Social. No entramos aquí a analizar las grandes diferencias que han 
existido entre unos tipos de pensiones y otras, que marginaban a los trabajadores del campo y al servicio doméstico, y marginan todavía a las viudas. Tampoco entramos en el método que se ha seguido para igualar pensiones mínimas, que se ha hecho a base de reducir el poder adquisitivo de las pensiones medias o altas, lo cual lesiona los derechos adquiridos por esas personas, cuando además la mayor parte de dichas pensiones altas serían consi. deradas un salario bajo por cualquier persona perteneciente a la población activa.

Las pensiones del Fondo Nacional de Asistencia Social constituyen unas pequeñas ayudas para aquellas personas que no tienen derecho a ninguna otra pensión, que carecen de rentas de cualquier tipo. Son pensiones a todas luces insuficientes y que sin embargo constituyen la única fuente de ingresos para muchos miles de ancianos.

\section{El entorno familiar del anciano}

Las formas sociales de vida no dependen totalmente de las voluntades de los sujetos, sino que están en función de los procesos sociales de producción. Así, el modo de producción capitalista adapta la estructura familiar a sus necesidades productivas. En su esquema el productor-varón debe mantener a su mujer y sus hijos, a los que debe preparar para integrarse en el proceso productivo. El padre tiene como función, además de producir él, preparar fuerza de trabajo. Este esquema, además, deja completa libertad al hijo para formar su propia célula familiar o, simplemente, abandonar el hogar familiar y organizar su existencia separadamente. No existe obligación de atender al padre en su vejez. Ni tampoco hay ningún papel importante reservado al anciano. Teóricamente es el Estado quien debe velar por él.

Los valores sentimentales y afectivos suplen en la mayor parte de los casos esa falta de lugar social del anciano.

El hecho del envejecimiento puede sucederle al anciano, bien en su pueblo de origen, en una ciudad a la que acaba de llegar o en una ciudad en la que vivió toda la vida.

Cuando el anciano se queda en el campo con alguno de sus hijos el problema vital y familiar no es grave. Posiblemente es suplantado en su papel de jefe de familia en la medida en que pierde fuerza y energía para dirigir la actividad y queda relegado a un segundo lugar. No obstante los problemas vitales que ello puede representar con frecuencia, es un proceso lento e insensible y en cualquier caso no hay un salto brusco de la actividad a la inactividad. El problema es, en cambio, muy grave en el campo cuando se quedan los ancianos solos, particularmente en pueblos donde no queda ya casi ningún joven. Cuando la emigración de los jóvenes se acompaña también de la de los mayores se presentan con frecuencia graves problemas de integración, 
pérdida de objetivos vitales o desorientación, siendo estos casos particularmente problemáticos; cuando el envejecimiento se produce en la ciudad pueden plantearse los problemas de una vivienda deficiente y el alejamiento de los hijos, entre otros.

El problema principal se plantea cuando el anciano es muy mayor, está impedido, no puede vivir en su propia casa, necesita que alguien le atienda constantemente, y en cambio la familia no tiene tiempo para dedicarle. Otros problemas no tan imperiosos pero no menos molestos para aquellos que se quejan de ellos, son las molestias que el hecho de tener un anciano en casa permanentemente provoca, por falta de libertad, por interferencia en la educación de los hijos y, por supuesto, por carga económica, si bien ésta puede tenerse igualmente aunque no se conviva con el hijo. Es fundamentalmente en estos casos cuando existe la tendencia a pensar en el internamiento del anciano en una institución.

A nivel general no existen, con respecto a la situación familiar de los ancianos en España, prácticamente ningún tipo de datos, ni en los informes FOESSA de 1970 y 1975, ni en los estudios GAUR sobre la situación social del anciano en España. Por ello es preciso recurrir a los pocos datos directos que existen y a indicadores indirectos relacionados con el tema, como la evolución del papel social de la mujer y su posible integración en el mundo del trabajo, y, por supuesto, es preciso aludir a los centros institucionales donde desaparece la estructura familiar.

La forma de vida familiar de los ancianos (tabla 2) puede ser de: soledad, familia nuclear o familia plurinuclear. Los ancianos solos, estarían dentro del grupo de hogares sin núcleo. De ese 10,6 por 100 , alrededor de un 3 por 100 son personas ancianas, ya que en España hay unos 350.000. La tendencia en los países desarrollados, sobre todo los anglosajones, es a aumentar ese porcentaje de personas solas, y lógicamente el de personas ancianas solas. Entre el 59,4 por 100 de familias nucleares pueden estar numerosas familias de matrimonios ancianos con o sin hijos solteros. Pero lo que es más curioso destacar de esta tabla es que el 20,6 por 100 de los núcleos familiares españoles son nucleares ampliados o incluso plurinucleares. Quiere ello decir que es aún bastante frecuente la familia más que nuclear y puede estimarse que buena parte de casos corresponden a ancianos y ancianas que viven con sus familiares.

Un hecho importante que posibilita la atención de los ancianos, especialmente cuando necesitan cuidados bastante continuados, es la presencia permanente en el hogar de alguna persona, que típicamente ha sido una mujer. La incorporación de la mujer al trabajo puede dar al traste con la permanencia de las personas ancianas en los domicilios de sus familiares. Independientemente de los servicos de ayuda comunitaria que puedan crearse, la situación no es por el momento tan alarmante. La proporción de mujeres que trabajaban en España en 1971 era del 28 por 100 . Aunque esta tasa sea la 
mitad o menor de la de otros países de Europa?, no parece que vaya a aumentar rápidamente.

\section{TABLA 2}

Distribución de la población española, por tipos de familas, en 1970

\begin{tabular}{|c|c|c|}
\hline & $\begin{array}{l}\text { Cifras } \\
\text { absolutas }\end{array}$ & $(\%)$ \\
\hline $\begin{array}{l}\text { Hogares sin nucleo familiar (una o varias per- } \\
\text { sonas ocupando una vivienda) } \ldots \ldots \ldots c c c c\end{array}$ & 940.053 & 10.6 \\
\hline 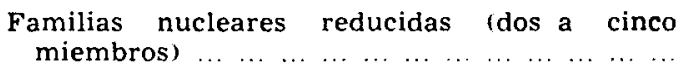 & 5.258 .255 & 59.4 \\
\hline $\begin{array}{c}\text { Familias nucleares } \\
\text { miembros! } \\
\end{array}$ & 826.168 & 9.3 \\
\hline $\begin{array}{l}\text { Familias nucleares ampliadas (un núcleo fami- } \\
\text { liar con otros parientes, huéspedes, etc.) } \ldots\end{array}$ & 1.313 .284 & 14.8 \\
\hline 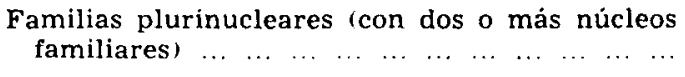 & 515.900 & 5,8 \\
\hline $\begin{array}{llllllllll}\text { TOTALES } & \ldots & \ldots & \ldots & \ldots & \ldots & \ldots & \ldots & \ldots\end{array}$ & 8.853 .660 & 100,0 \\
\hline
\end{tabular}

Fuente: INE, Censo de la población de España, 1970 (Madrid: INE, 1974), vol. III, página 4.

\section{Las viviendas de los ancianos y los centros institucionales}

Con frecuencia las viviendas de los ancianos son antiguas y, por consiguiente, deterioradas y carentes en buena parte de las innovaciones técnicas más avanzadas. Los ascensores y el sistema de calefacción acostumbran a ser los problemas más importantes. No obstante, la vida del anciano está sentimentalmente pegada a las paredes y muebles de la vivienda donde ha transcurrido su existencia. Afortunadamente existen otros vínculos, porque la gran mavoría de los ancianos de Europa Occidental no pueden acceder a la compra o alquiler de una vivienda nueva, lo cual viene determinado por su situación económica ${ }^{8}$. Aparte de la convivencia con sus familiares, la sociedad puede ofrecer a los ancianos dos alternativas: la construcción de viviendas especiales para ancianos y la creación de instituciones asistenciales totales.

' Por ejemplo: USA, 46 por 100; Suecia, 45,5 por 100; Gran Bretaña, 50 por 100; Francia, 39,4 por 100; Checoslovaquia, 64,2 por 100; Hungría, 59,9 por 100.

" La situación de los países del Este es muchísimo peor; la convivencia bi y trigeneracional no es, en muchos casos, una opción, sino la única solución. 
Los lugares donde viven los ancianos que no han cambiado de domicilio son generalmente antiguos, lo que significa techos altos, puertas grandes, deficiente calefacción y ascensores, falta de agua caliente y tamaño grande para sus necesidades. En el exterior de la vivienda ocurre que las otras casas también son antiguas, el barrio en su conjunto lo es y sus habitantes tienen un promedio de edad elevado, es decir, casi no hay población infantil. Todo el entorno es viejo y ello, aparte de los recuerdos sentimentales, afecta a la psicología del anciano y lo aparta de la percepción real de la dinámica social. En cierto modo va quedando marginado individualmente y como grupo.

La mayor parte de las construcciones que existen o se hacen específicamente para ancianos o se enmarcan dentro de la línea de la marginación. El principal grupo lo constituyen las residencias de ancianos, con frecuencia antiguas, dirigidas por personal a veces poco preparado, donde no se estimula al anciano a llevar una vida activa, sino que simplemente se le mantiene en vida. A veces los centros son nuevos, pero muy grandes y masificados y ubicados fuera de las ciudades, ya que el elevado coste del suelo obliga a buscar reductos más económicos para los ancianos. Aunque a veces se crea que las ciudades son lugares idóneos para los ancianos, realmente no lo son a su criterio y objetivamente son una manifestación clara del proceso de marginación, que puede ser económica y social en el caso de los centros antiguos o simplemente social en los nuevos. Las ciudades de ancianos y similares no hacen sino seguir la misma tónica.

Es por ello que las propuestas que persiguen la integración del anciano en la sociedad a base de nuevas construcciones pensadas en sus necesidades pero mezcladas con las otras, o bien cuando sea el caso, de la creación de miniresidencias deben siempre imponerse contra-corriente de los intereses del sistema, pero también es cierto que van siendo comprendidas lentamente por los responsables de las políticas sociales, aunque los imperativos socio-económicos del sistema social tienden a mantenerse. En algunos países existe ya una ley de construcción de viviendas adecuadas para ancianos. En España sólo existe un Decreto de reciente publicación que obliga a reservar algunas viviendas en los bloques de grandes dimensiones?

La cantidad de centros de acogida de personas ancianas es bastante imprecisa ${ }^{10}$. Ello es debido en parte a la difícil distinción en ocasiones entre hospital y residencia. Se ha constatado en numerosos casos que hospitales

${ }^{9}$ Boletín Oficial del Estado 28 de febrero de 1979, Real Decreto del Mínisterio de Obras Públicas y Urbanismo por el que se modifica la legislación anterior referente a viviendas de minusválidos.

${ }_{10}^{10}$ El autor está realizando actualmente por encargo de Iberhospitalia, S.A., un estudio sobre el tema. En la realización del censo, en el que se pidió la facilitación de datos a los organismos provinciales, se hallaron centros que estaban cerrados hacia diez años. En algunas comunidades existían catálogos fiables. Actualmente tanto a nivel estatal como en las distintas comunidades autónomas se están haciendo esfuerzos importantes en este sentido. 
municipales de pequeñas poblaciones en realidad no son tales, ya que carecen de instalaciones hospitalarias, con lo que no son ciertas ni las estadísticas de camas de hospital ni las de camas de residencias. Esto agravaría, por otro lado, la falta de camas hospitalarias en el país, que ya es considerable.

Según el informe GAUR, el número de centros era en 1971 de 700 aproximadamente, con unas 40.000 camas, lo que suponía en aquel año una tasa del 1,4 por 100 de personas ancianas ". En otros países de Europa esta tasa varía considerablemente en función de que se ponga el énfasis en la asistencia a domicilio o en la asistencia en centros específicos. Así Gran Bretaña tiene una tasa del 2 por 100; Dinamarca, 3 por 100; Francia, 4,8 por 100; Suiza, 5,9 por 100, y Finlandia, 6,5 por 100 .

En España puede estimarse que la situación está cambiando en los últimos años con el incremento de la conciencia social, la participación decidida del «Servicio de asistencia al pensionista» y con el incremento de posibilidades económicas de la comunidad en su conjunto y de algunos - no todos- ancianos en particular. Con frecuencia los nuevos centros son por oposición a los antiguos desproporcionadamente provistos de medios, quizá demasiado grandes. El resto de los centros siguen con graves problemas económicos, que en muchos casos provocan unas condiciones de vida no muy dispares a las de siglos pasados.

En este campo las corrientes están cambiando rápidamente. Cuando todavía se están construyendo grandes centros confortables ya se están poniendo en cuestión, proponiendo a cambio soluciones que eviten el internamiento y que, en los casos en que sea imprescindible, se haga en centros más pequeños y familiares, características que, paradójicamente, debidamente res. taurados reúnen más los antiguos centros que los nuevos.

"El texto del informe GAUR fue publicado en 1976, pero los datos sobre las residencias son de 1971. Según datos provisionales del estudio al que aludimos, en la nota cinco podemos estimar que actualmente España dispone aproximadamente de dos camas por cada 100 ancianos. 
BIBLIOGRAFIA BASICA

José A. Aguirre, et alii, Tercera Edad (Madrid: Karpos, 1977).

Isidoro Alonso Hinojal. Sociología de la familia (Madrid: Guadiana, 1973).

F. J. Alonso Torres, "Marginación social de la tercera edad en España", Revista de Fomento Social. 124 (1976): 427-434.

Ignacio ARAGó, com., "Los ancianos, el 10 por 100 de nuestra población". Estudios sobre hospitales, 32.

Asociación COORdinadora para la ANCIANmad. Primer Simposium Tercera Edad (Barcelona, 1976), mimeo.

Marcelle AuclaIR, Hacia una vejez dichosa (Barcelona: Iberia, 1972).

Giovanni Berlinguer, Medicina y politica (Buenos Aires: Cuarto Mundo, 1975).

Simone de Beauvolr, La vejez (Buenos Aires: Editorial Sudamericana, 1970).

J. Borwinck, Cognitive Processes in Maturity and Old Age (Nueva York: Springer, 1967).

J. Bourgeors, "Le vieillissement de population", Population. 2 (1972): 209-239.

Robert H. BRinstock y Ethel Shanas, Aging and the Social Sciences (Nueva York: Van Nostrand Reinhold, 1977).

R. CanLlor, "Vivre le troisième age", Economie et Humanisme, 2 (1972): 2-16.

Diego Diaz, La última edad (Pamplona: Eunsa, 1976).

James R. Elltot, La vida en el hospital (Barcelona: Emporium, 1976).

Bernard ENNUYer y Michele Troude. Il y a toujours des hospices de vieux (París: Lutter-Sock, 1977).

EspiNós, et alii, "La unidad geriátrica", Estudios sobre hospitales, 57 (1973).

Exron, et alii, Nutrition of Housebound Old People (Londres: King Edward's Hospital, 1972).

Asociactón Española de Gerontología. X Congteso Nacional de Gerentología y Geriatría. Valencia, 1977 (Madrid: Garví, 1978).

Minna FIELD, Aging With Honor and Dignity (Springfield-Illinois: Charles C. Thomas, 1968).

FUNDACIón FOESSA, comp., Informe sociológico sobre la situación social de Espa$\bar{n} a, 1970$ (Madrid: Euramérica, 1970).

FUNDACIón FOESSA, comp., Estudios sociológicos sobre la situación social de España, 1975 (Madrid: Euramérica, 1976).

E. García Río, "Valoración presente y futura de las necesidades de los ancianos de Barcelona", Labor Hospitalaria, 160 (1976): 70-73.

GAUR, La situación del anciano en España (Madrid: Confederación Española de Cajas de Ahorros, 1975).

Generaltiat de Catalunya, Politica per a la Tercera Edat (Barcelona: Generalitat de Catalunya, 1979).

Irving GofrmaN, Internados (Buenos Aires: Amorrortu, 1972).

F. Gros, "Les personnes âgées en France", Economie et Humanisme, 157 (1964): 72-79.

Groupe Lyonnais d'Etudes Medicales, La vejez, problema de hoy (Madrid: Razón y $\mathrm{Fe}, 165$ ).

GERoNr, comp., "Primeras jornadas internacionales de gerontología", Hacienda $y$ Hogar, 44 (1978).

Kenneth Hazpli, Social and Medical Problems of the Elderly (Londres: Hutchinson Medical Publications, 1965).

A. HIRsCH, "La consommation des personnes âgées et sa contrepartie en population active", Population, 6 (1973): 1129-1153.

Hoch Zubin, Psicopatologia de la vejez (Madrid: Morata, 1960 ).

Hodkinson, Geriatria (Barcelona: Marín, 1977).

INE, Anuario estadistico de España, 1978 (Madrid: Ministerio de Economía, 1978).

ISPA, Informe sociológico sobre la ancianidad en Cataluña (Barcelona, 1976). mimeo.

ISPA, Problemática social de la tercera edad en las islas Baleares (Barcelona: Caixa de Pensions per a la Vellessa i d'Estalvis, 1978). 
F. Jiménez Herrero, "Preparación para la jubilación", Revista de Sanidad e Higiene Pública (julio 1975): 635-646.

Elisabeth Kubler Ross, On Death and Dying (Nueva York: Mac Millan, 1969).

P. Lefrebve, "Lhospitalisation des personnes âgées", Revue Hospitalière de France (enero 1975): 55-100.

Jacques Leclerce. La joia d'envellir (Barcelona: Publicacions de l'Abadia de Montserrat, 1975 ).

Enrique Luño, comp., La ancianidad (Barcelona: Caixa de Pensions per a la Vellesa i d'Estalvis, 1968).

S. Martinez Tornes, "Vejez y convivencia generacional", Arbor (julio-agosto 1972): 51-62.

J. MASLowsKI, "L'activité professionnelle aux âges élevés". Population, 1 (1972": 51-67.

M. MAYEN, "La population des hospices et des maisons de retraite". Population, 1 (1972): $69-82$.

Alan MAY, et alii, Attitudes Toward Nursing Homes and Other Facilities for Meeting Health Care Needs After Retirement: Scott County and Fort Smith. Arkansas (Arkansas: University of Arkansas Press, 1975).

Amando DE MrcuEl, Manual de estructura social de España (Madrid: Tecnos. 1974). Jesús M. DE Mrguet. El ritmo de la vida social (Madrid: Tecnos. 1973).

National Health Counchi, Action on Chronic Illness (Nueva York: National Health Council, 1956).

Robert NESTA, Nuestro propio futuro (México: Euramérica, 1971 ).

B. L. Neugarten, Midle Age and Aging: A reader in Social Psychology (Chicago: University of Chicago Press, 1968).

OMS, Problemas de salud mental del envejecimiento $y$ de la vejez (Buenos Aires: OMS, 1959).

OMS, Planificación y organización de los servicios geriátricos fGinebra: OMS, 1974).

OMS, Psicogeriatria (Ginebra: OMS, 1972).

OMS, Simposium on Research and Welfare Policies for the Elderly IHerzlya, Israel, 1970), mimeo.

Paul Palllat, Sociologia de la vejez (Barcelona: Oikos-Tau, 1971 ).

P. Paillat, "Conditions de vie et besoins de ruraux àgés non agricoles", Population, 6 (1973): 1125-1128.

P. PaIllat, "La recherche gérontologique", Revue Internationale des Sciences Sociales, 2 (1968): 295-305.

Pastalon L., "How the Elderly negotiate their environment", Environments for the Aged: $A$ Working Conference on Behavioral Research. Utilitation and Environmental Policy (San Juan de Puerto Rico, 1971), mimeo.

J. Pernau Llimos. "La ancianidad, problema social de nuestro tiempo", Revista de Documentación Social (octubre-diciembre 1963), número monográfico.

Prccinelli, "Les établissements pour personnes âgées: Evolution de la carte sanitaire et liaison avec le maintien à domicile", Revue Hospitalière de France loctubre 1978): 1399-1427.

M. Powell, et alii, Community Planning for an Aging Society (Pensilvania: Hutchinson \& Ross, 1976).

Roland PREssat, Introducción a la demografía (Barcelona: Ariel, 1977).

B. RANDAZzo, "L'incidenza culturale nel comportamento degli anziani", Esperienze Socrali, 24 (1972): 161-169.

W. RILEY, et alii, Aging and Society: Vol. I, An Inventory of Research Findings; Vol. II, Aging and the Practicing Professions; Vol. III, The Sociology of Age Stratification (Washington: Rusell Sage Foundation, 1968, 1969 y 1972).

Kent RoNald, et alii, Research, Planning and Action for the Elderly (Nueva York: Behavioral Publications, 1972).

J. P. Roulleau, "Le troisième âge", Informations Sociales, 2 (1966): 28-29.

Rush-Presbyterian - St. Luke's Medical Center. A Methodology for Evaluation of Quality Life and Care in Long Term Care Facilities (Chicago: St. Luke's Medical Center, 1973). 
Alfred Sauvy, La població (Barcelona: Edicions 62, 1964).

SEYLE, H., The Stress of Life (Nueva York: McGraw-Hill, 1956).

E. SGRor, "Gli anziani nella società italiana", Esperienzi sociali, 2 (1967): 120-126.

B. R. Staton, Meals for the elderly (Londres: King's Foundation, 1971).

Tallavd, G. A., Human Aging and Behavior (Nueva York: Academic Press, 1968).

Paul Tourner, Learn to Grow Old (Nueva York: Harfer and Row, 1971).

S. R. Turbow, "Geriatric group day care and its effect on independent living: A thirty six month assesment", Gerontologist, vol. 15, núm. 6 (1975): 508-515.

Max WebEr, Ensayos de sociologia contemporánea (Barcelona: Martínez Roca, 1972).

C. S. WLDER, "Health characteristics of persons with chronic activity limitation". Vital and Health Statistics, 112 (1975): 1-14.

Heinz Woltereck, La vejez, segunda vida del hombre (México: Fondo de Cultura Económica, 1962).

N. E. Zinberg e I. Kaufman, Psicología normal de la vejez (Buenos Aires: Paidós. 1976). 
NOTAS 